\title{
Is the Social Action Programme in Pakistan Financially Sustainable?
}

\author{
Hafiz A. Pasha, M. Aynul hasan, Aisha Ghaus, and Ajaz Rasheed
}

\section{INTRODUCTION}

Earlier neoclassical, classical, or structuralist theories [due to Rostow (1960)] considered economic growth to be a result of the right quantity and combination of saving, investment, and foreign aid, with surpluses from the primary commodityproducing sectors being channelled into capital for further growth. Accordingly, the main constraint in these growth models has been the relatively low level of capital formation available. While the above paradigm has intuitive appeal, it, however, ignores the complementarity of social-political influences on the physical variables (i.e., capital, labour, etc.) in growth and development. Urquidi (1971) argued that the social progress of a nation is a necessary condition for sustained economic growth. It is now increasingly evident that the investment in the social sectors-primary education, basic health, housing, changes in land-tenure system, social security, better social relations-are as, if not more, important than the investment in the commodity-producing sectors or related infrastructure. In this context, Lloyd-Ellis (1993) noted:

Perhaps the most influential proposition that has come out of the postwar theories of economic growth is that the accumulation of human capital, in the form of educational expansion or otherwise, is a major determinant of overall GNP growth in both developed and less developed countries...(and) this expansion has contributed to aggregate economic growth and, where such investment programmes have been well-designed and implemented, the growth encouraged by them may well have offset any negative effect caused by increased taxation or debt burden.

Hafiz A. Pasha is Director, Institute of Business Administration, Karachi. M. Aynul Hasan is Economic Adviser, CIDA, and teaches at Acadia University in Canada. Aisha Ghaus is Research Economist, Applied Economics Research Centre, University of Karachi: Ajaz Rasheed is Systems Analyst, ISSP, Karachi.

Authors' Note: Research support was provided by Nadeem Ahmed, Nazia Bano, and Naveed Hanif. This study was funded by the Canadian International Development Agency (CIDA) and the authors wish to thank the Agency for providing financial support. The authors alone are responsible for any errors. 
The growth experienced by countries like Singapore, Malaysia, Indonesia, South Korea, Hongkong, and Taiwan is the result of investment in the social sectors, particularly education and health, and is a testament to this paradigm. If Pakistan is to become another Asian Tiger, it will have to educate and improve the health of its masses without compromising expenditures on these social services. In recent years, with the cooperation of donors, Pakistan has taken some positive initiative in the form of the Social Action Programme (SAP), whereby it has committed to improve the social conditions of the masses. Under this accelerated programme, federal as well as provincial governments have earmarked some of their public expenditures for key social services, namely, primary education (for girls), basic health (in rural areas), clean water, sanitation, and population planning.

Thus, in view of the above, the important public policy issues that need to be investigated are:

- If the existing social services are to be expanded and improved, and if accelerated construction programmes for more schools, basic health units (BHUs), and other social infrastructure are to be undertaken, what implications will this have on budget outlays?

- Given high budget deficits, can the government, particularly provincial governments, afford recurring expenditure liabilities (e.g., teachers, doctors, nurses, medication, books, etc.) on an ongoing basis due to SAP?

- Are the present public institutions in the country capable of handling such an accelerated expansion of facilities as proposed by SAP?

All these public policy questions are critical in terms of the long-run sustainability of the Social Action Programme. This study attempts to address these specific issues based on an Integrated Social Policy Macroeconomic Model developed elsewhere. In particular, as an example, we investigate the impact of SAP on the macro-economy in the form of a three-year special annual development programme for the provinces. We also explore alternative avenues to examine the possibilities of making SAP sustainable in the long-run.

\section{PAKISTAN'S STANDING IN TERMS OF SOCIAL INDICATORS}

How is Pakistan's performance in social indicators in relation to other neighbouring countries? Does Pakistan spend enough on her human resource development? These questions are critical, as the "human capital endowment" of a nation plays a pivotal role in the growth and development of the country. More significantly, acting as a complement with physical capital and natural resources, human capital provides long-term sustainability in economic and social development. This human capital development, in turn, demands a world where no human being is 
denied of basic health care and, more importantly, no child is deprived of elementary primary education.

Despite an impressive economic growth of over 6.5 percent per annum, the performance in the social indicators of Pakistan has been inadequate. In relation to eleven other comparable countries considered in Table 1, Pakistan's population growth rate has been the highest at 2.9 percent. The other most discouraging social indicator has been the literacy rate, particularly for females, which stood at a meagre 22 percent in 1992. Although Pakistan's overall literacy rate has increased from 21 percent to. 36 percent in the last two decades, it is still one of the lowest, next to Nepal as shown in Table 1. In fact, the first-grade intake rate ( 77 percent) is also the lowest among the countries considered for the analysis.

Contrary to this, countries like Nigeria and Bangladesh, with a significantly lower per capita GNP than Pakistan, have a much higher female and overall literacy rate and first-grade intake rates, as reported in Table 1 . This indicates that there are many countries with low per capita income but higher human development indicators than Pakistan.

Another rather serious educational problem of developing nations is the very high percentage of students who drop-out before completing a particular cycle. The drop-out problem is more serious mainly because of poverty and ignorance. This situation is reflected in Table 1, which ranks Pakistan as the second-lowest country among those whose students complete primary level. There are actually more mouths to be fed relative to the income-earners. Hence, as soon as the young ones are capable of fend for themselves, they are asked to earn, rather than involve themselves in the so-called "unproductive work of learning".

As the above analysis and data suggest, the importance of the social sector has not been recognised in the past by the policy-makers in Pakistan as a priority sector. It appears that there has been a lot of rhetoric, and no concrete efforts have been made to increase public spending in the social sector while, during the same period, many countries in the region have invested heavily in health, education, training, and skill formation of its people.

In summary, based on a cross-country comparison of various indicators, it is clear that Pakistan's performance in the social sector is less than adequate. Furthermore, Pakistan's spending on this sector is also one of the lowest in the region. In the present environment of high budget deficits, concerns have been voiced by the provincial governments about the sustainability of the recently initiated Social Action Programme (SAP). By and large, provincial governments in Pakistan are primarily responsible for the delivery of basic social services (e.g., education, health, water supply, sanitation, etc.). These governments rapidly realised that while 


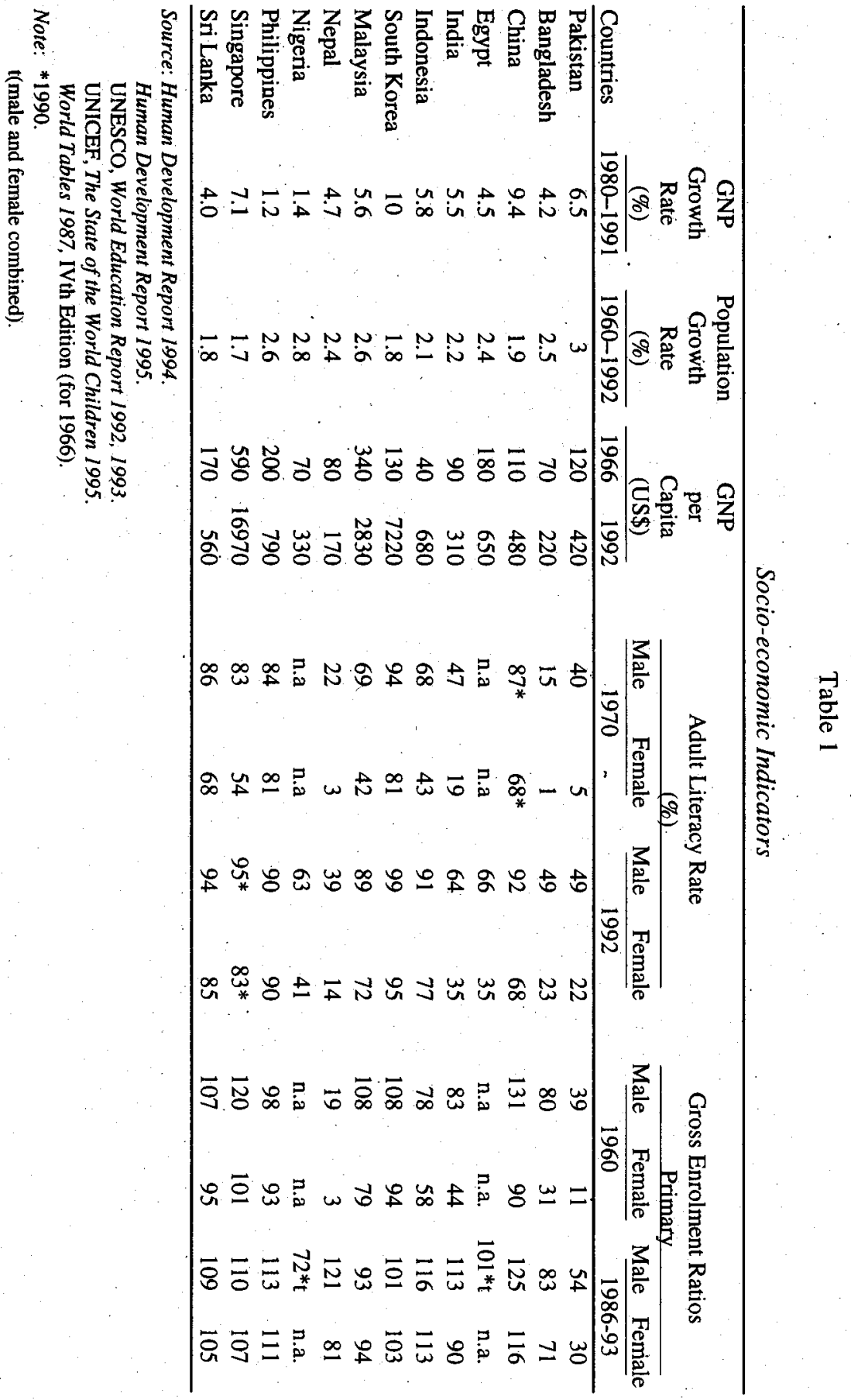


accelerated development funding could potentially become available through $S A P$, there was no obvious source of revenue for financing the downstream operation and maintenance expenditures of the facilities created, especially since some of the social sectors like education and health are highly recurring expenditure-intensive. The lack of recurring funding could, therefore, adversely affect the fiscal position of provincial governments and require either larger inter-governmental revenue transfers or higher resource mobilisation.

In order to investigate these key public policy issues, it is essential to develop a planning framework which clearly highlights the future implications of expanded development outlays in the social sectors on recurring expenditures. Furthermore, among other things, it will also enable us to quantify the implications of programmes like the $S A P$ for the budgetary position of provincial governments, and derive thereby the need for additional resources with provincial governments.

\section{SALIENT FEATURES OF THE MODEL}

The model used in this study consists of about 200 equations and covers several aspects of the economy. ${ }^{\prime}$ One of the unique features of the model is that for the first time in Pakistan, it has provided a planning tool wherein the social, public finance, and macro-economic dimensions of the economy have been integrated under one system. The model is dynamic, rich in specification, and based on a pragmatic approach. Because of its highly disaggregated character, covering all three levels of government (federal, provincial, and local), the model is capable of predicting variables in greater detail even at the level of provision of individual social services. It should be noted that such a disaggregation of the model at the provincial level, in terms of revenue and expenditures on social services (e.g., schools, hospitals, doctors, teachers, enrolment, etc.), is in fact necessary particularly in order to analyse the impact of $S A P$ on the macro-economy. The principal links of the model can be traced as follows.

\section{Macroeconomy $\longrightarrow$ Public Finance $\longrightarrow$ Social Sector Development}

The key link here is that developments in the macro-economy influence the growth of tax bases of taxes (including divisible pool taxes) and thereby affect the fiscal status of different governments. Also, the overall rate of inflation in the economy affects the growth of public expenditure. The level of government expenditure could exert a demand-side effect on national income while the size of the overall budget deficit, of the federal and provincial governments combined, influences the rate of monetary expansion and, consequently, the rate of inflation in (1995).

${ }^{\text {I}}$ For details on the specification and other aspects of the model, readers may refer to Pasha $e$ al. 
the economy. The availability of resources, both external and internal, determines the level of development and recurring outlays to social sectors by different levels of government, especially the provincial and local governments.

\section{Social Sector Development $\longrightarrow$ Macroeconomy $\rightarrow$ Public Finance}

Higher output of educated workers and their entry into the labour force raises the human capital stock and could contribute to improvements in productivity and higher growth rate of output in the economy. Similarly, an improvement in public health standards may also have a favourable impact on production. A vital link in the model is between the rate of social sector development and the state of public finances, especially of provincial governments, in terms of the implications on the level of debt servicing and recurring expenditures. Demographic and other socioeconomic changes impact on the demand for social sector facilities like schools, hospitals, etc., and thereby influence the level of social sector outputs.

\subsection{Provincial Governments' Role in the Model}

Based on the above linkages, it is possible to get a more comprehensive understanding of how provincial governments fit into the national context both in terms of the major elements of the environment that impact upon them. and in terms of how their actions in turn affect the macro-economy (see Flow Chart 1).

Provincial governments are affected by changes in the level of output in the productive sectors of the economy, viz., agriculture, manufacturing, and services. These changes influence the growth of tax revenues directly and indirectly, via the impact on revenues from federal divisible pool taxes like income tax, sales tax, and excise duties. Since the bulk of the revenues of the provincial governments are in the form of fiscal transfers from the federation, developments in the national economy have a vital bearing on the budgetary position of provincial governments. Similarly, developments on the monetary front are of direct concern to provincial governments as they influence the rate of inflation in unit costs and wage rates, while changes in interest rates have consequences on debt servicing liabilities.

Proyincial governments influence the macro-economy in a number of ways. First, via their expenditure, which affects the level of national income, and through investments in economic and social infrastructure, which contribute to the rate of economic growth on a more long-term basis. Second, their combined revenue surplus or deficit influences the overall national budget deficit and the resulting monetary expansion and inflation in the economy. Provincial governments also influence behaviour of local governments via fiscal transfers and provision of competing services. 
In particular, the model carefully depicts the pattern of inter-governmental fiscal relations in the country (see Flow Chart 2). It allows for various types of flows of funds from the federal government to the provincial governments including divisible pool transfers, special transfers (like hydro-electricity profits), grants and cash development loans, and for the reverse flow-from the provincial governments to the federal government- of debt servicing. Similarly, flows of funds between provincial and local governments are also modelled.

The basic conclusion is that projections of the future fiscal status of provincial governments, collectively or individually, and assessment of the fiscal consequences of the level and composition of annual development programme can only be made in the context of a model which captures all the above-mentioned links. The model developed by us is a major step forward in achieving this objective.

\section{POLICY SIMULATION RESULTS}

In order to keep the discussion as simple and intuitive as possible, in the subsequent sections, only the important linkages and the impact of a given $S A P$-type policy initiative on key relevant variables will be presented with the help of flow charts and tables containing actual changes in the variables.

\section{1. $S A P$ with Development Expenditures}

In this section, we investigate whether the SAP-type plan with only development expenditures will be able to produce long-term sustainable results for the social sectors. This is critical as many of the special development programmes such as $S A P$ were initially designed with no specific provisions for recurring expenditure liabilities. In other words, schools or basic health centres were constructed without giving due consideration to the ongoing needs for teachers, books, doctors, nurses, medication, etc. As before, we first explain the transmission mechanism using a flow chart, through which the above policy will permeate the macro-economy, and subsequently analyse the impact of such a policy in terms of numerical figures. For pedagogical reasons and to get a deeper insight, we assume a three-year SAP with one billion rupees additional investment every year, of which fifty percent is borrowed from the donor and the rest generated domestically by the federal government.

Flow Chart 3 shows the schematic linkages of the above type of $S A P$ in the form of a special $A D P$, which, of course, comes from both external and internal borrowing. These two types of borrowing each year will add to the overall deficit of the economy. Since the implementation of SAP is the responsibility of the provincial governments, federation will transmit $S A P$ development funds via special provincial development transfers. These funds, subsequently, based on some guidelines, will be 


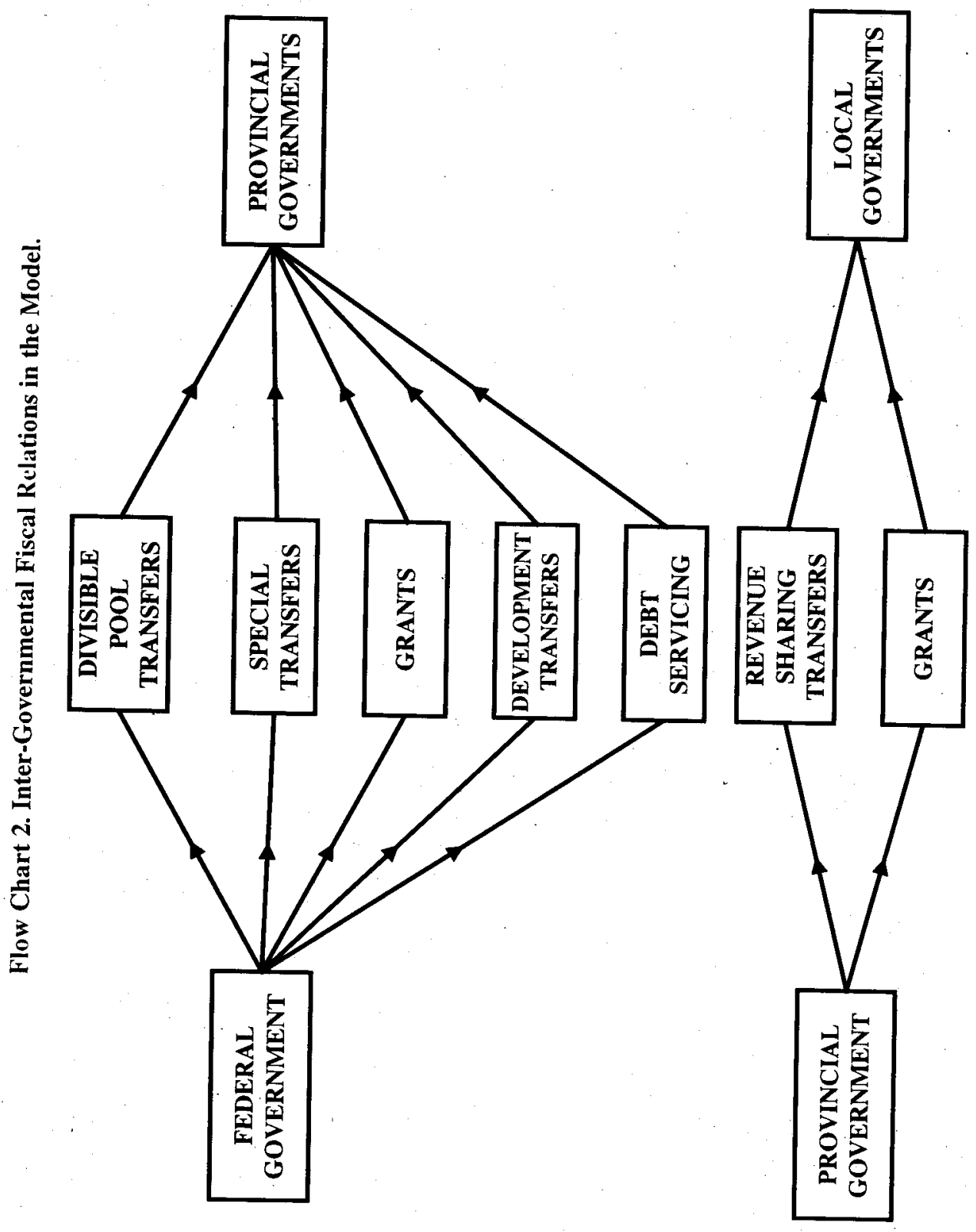




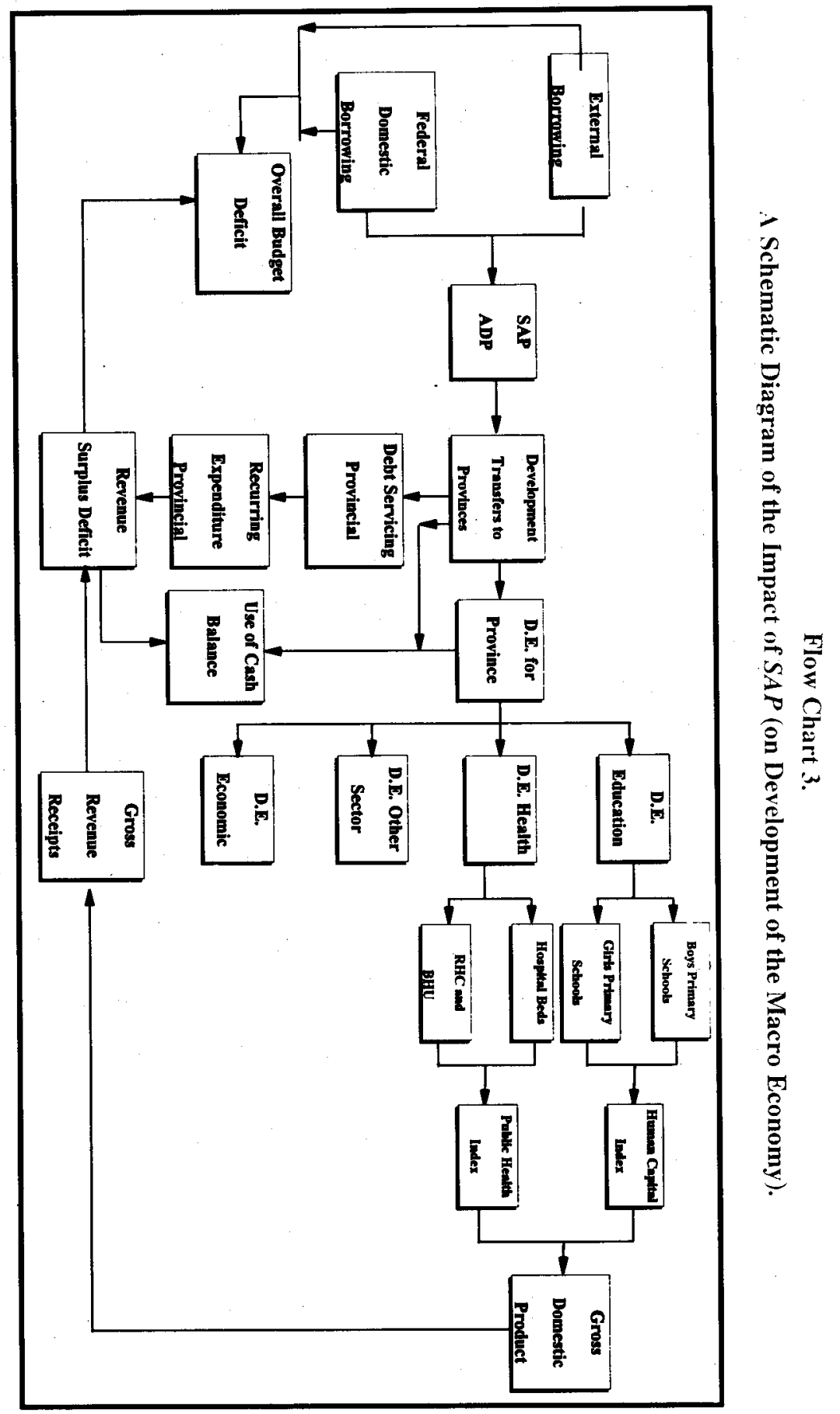


divided into three specific social programmes, namely primary schools, BHUs and $R H C s$, and other social services (e.g., clean water, sanitation, and population planning). Construction of this physical social infrastructure is expected to have an impact on both human capital and public health endowments of the society (through educated and healthy labour force) and, thus, in due course, it is expected to have an impact on the economy's broad macro-economic aggregate such as the $G D P$. Higher $G D P$ will subsequently enhance the tax bases, thus increasing the revenues of the provincial governments. An improved revenue position of the provincial governments may also help improve the revenue surplus/deficit of these governments. On the other hand, the development transfers to the provinces will also have immediate implications for provincial debt servicing liabilities, placing a negative effect on the revenue surplus/deficit of these governments. Thus, the net effect on the revenue surplus/deficit of the provincial governments will be ambiguous. However, the overall deficit of the economy will unambiguously rise at least in the period when the federation is engaged in borrowing to finance $S A P$.

The numerical values of the impact of the above policy on key variables are reported in Table 2. For convenience, we have provided simulation results for the short-run (1994-95), long-run (2002-03), and baseline period (1992-93). As expected, the social infrastructure variables, namely, schools, hospital beds, and RHCs, have improved and this is reflected in higher student participation rates, human capital, and public health indices. It is, however, important to note that the above type of $S A P$, having no provision for recurring expenditures (e.g., teachers, doctors, etc.), will eventually end up providing facilities of a lower quality. This is manifested in the decline of ratios of teachers to school, doctor to beds, and RHCs, as shown in Table 2.

As for the fiscal variables, provincial debt servicing liabilities will increase up to rupees one-half billion and about Rs 200 million in use of provincial cash balances by the year 2002-03. Recurring liabilities have also increased but not commensurate with the initial development expenditures. This is due to the fact that no funds have been earmarked for recurring expenditure. It is also interesting to note that, due to improved provision for human capital, the $G D P$ has increased by over one-and-half billion and this has also resulted in improved gross revenue receipts by over half-abillion by the year 2002-03. The overall deficit position of the economy has deteriorated by about four billion rupees.

In summary, then, a SAP policy, with only development expenditures, is expected to elevate the provision of social physical infrastructure (schools, beds, (RHCS) without having a corresponding increase in other recurring-type inputs, namely, teachers, books, doctors, nurses, medication, etc. Thus, as a result, initially the performance of the social sector may improve; however, as soon as the development programme ends after three years, the quality of provision of social 
Table 2

Impact of SAP Development Expenditure on Macro-economy

\begin{tabular}{|c|c|c|c|}
\hline & 1992-93 & $1994-95$ & $2002-03$ \\
\hline \multicolumn{4}{|l|}{ A. Social Sector Variable } \\
\hline \multirow{4}{*}{ Primary Participation Rate } & 99.42 & 0.00 & 0.05 \\
\hline & & 104.13 & 134.47 \\
\hline & 45.21 & 1.38 & 8.95 \\
\hline & & 49.58 & 67.70 \\
\hline \multirow[t]{4}{*}{ Teacher to School Ratio } & 2.29 & 0.000 & 0.002 \\
\hline & & 2.376 & 3.085 \\
\hline & 3.68 & -0.318 & -0.308 \\
\hline & & 3.542 & 3.258 \\
\hline \multirow[t]{2}{*}{ Hospital Beds } & 52228 & 0 & 187 \\
\hline & & 55486 & 68424 \\
\hline \multirow[t]{2}{*}{ Rural Health Centre (RHC) } & 1375 & 0 & 136 \\
\hline & & 1739 & 3534 \\
\hline \multirow[t]{2}{*}{ Doctor to Bed Ratio } & 0.438 & 0.000 & -0.001 \\
\hline & & 0.472 & 0.621 \\
\hline \multirow[t]{2}{*}{ Doctor to RHCs Ratio } & 8.38 & 0.000 & -0.242 \\
\hline & & 7.974 & 6.704 \\
\hline \multirow[t]{2}{*}{ Human Capital Index } & 136.22 & 0.02 & 0.70 \\
\hline & & 139.45 & 189.88 \\
\hline \multirow{2}{*}{ Public Health Index } & 241.38 & 0.34 & 5.83 \\
\hline & & 272.83 & 410.64 \\
\hline \multicolumn{4}{|l|}{ B. Fiscal Variables } \\
\hline Provincial Dev. Expenditure (Social) & 18,122 & 1,009 & 144 \\
\hline Provincial Rec. Expenditure (Social) & 52,442 & 205 & 663 \\
\hline Debt Servicing & 20,548 & 203 & 502 \\
\hline Gross Revenue Receipt & 91,223 & 6 & 587 \\
\hline Use of Cash Balances & 4,239 & 169 & 200 \\
\hline \multicolumn{4}{|l|}{ C. Macro Variables } \\
\hline Overall Budget Deficit & $\mathbf{9 3 , 5 2 0}$ & 1,307 & 3,841 \\
\hline Value-added in Agriculture & 122,894 & 12 & 508 \\
\hline Value-added in Manufacturing & 85,534 & 3 & 340 \\
\hline Value-added in Other Sectors & 277,337 & 12 & 651 \\
\hline Gross Domestic Product & 542,291 & 28 & 1,638 \\
\hline
\end{tabular}

Note: Numbers in Italics indicate Baseline Simulation Results.

Numbers in sections B \& C represent change from the baseline simulation due to the Rs 1 Billion increase for three consecutive years. 
services will decline due to the lack of necessary recurring inputs. The long-term consequences of such a programme may result in additional schools without enough teachers and hospitals with inadequate supply of medicines, doctors, and nurses. Hence, though this type of $S A P$ programme may not impart a greater burden to the overall deficit of the economy, such a programme will certainly not achieve the stipulated long-run objective of improving the social conditions of the masses.

\section{2. $S A P$ with Development and Recurring Expenditures}

If the $S A P$-type plan requires both development and earmarked recurring expenditures to produce the intended long-run positive results in the social sectors, then the question arises whether such a programme will be sustainable from the budgetary point of view. In other words, with ongoing recurring expenditures liabilities, can the provincial governments be able to meet the additional expenses from the existing pot, particularly when some of the provinces are already experiencing deficits? In addition, what will happen to the provincial debt servicing liabilities and the use of cash balances when the State Bank of Pakistan has already imposed a ceiling on such borrowing facilities. Using Flow Chart 4 and Table 3, we examine the impact of the above policy specifically on the issue of the sustainability of SAP.

Under the above type of policy, the $S A P$ funds transferred by the federation to the provincial governments will be divided into both development and recurring outlays for the social sectors, as shown in Flow Chart 4. Once the stipulated period (say three years) for $S A P$ is over, the ongoing future recurring expenditure liabilities will become the provincial governments' responsibility. It should be noted that these additional SAP expenditures (both development and ongoing recurring outlays) are expected to boost the provision of the social services, resulting in improved human capital and public health indices, and thus a higher GDP. A higher GDP is also expected to improve the revenue position. At the same time, in the absence of any fiscal effort or other alternatives, the provincial governments' additional recurring expenditure liabilities will exert a negative impact on the revenue/surplus position, which may force these governments to engage in borrowing from the State Bank in terms of use of cash balances. This activity of the provincial government will also influence the overall deficit of the economy, as shown in Flow Chart 4.

Table 3 reports the numerical values of key variables due to the above policy. It is interesting to note that while earmarking of recurring expenditures improved the provision of the delivery of social services in terms of more teachers to school, doctors to beds and RHC ratios, the fiscal budgetary positions of the provincial governments deteriorated. Debt servicing liabilities as well as the use of cash balances of the provinces in the case of the present type of SAP financing scheme have increased by over 50 percent and 100 percent, respectively, as compared to the 


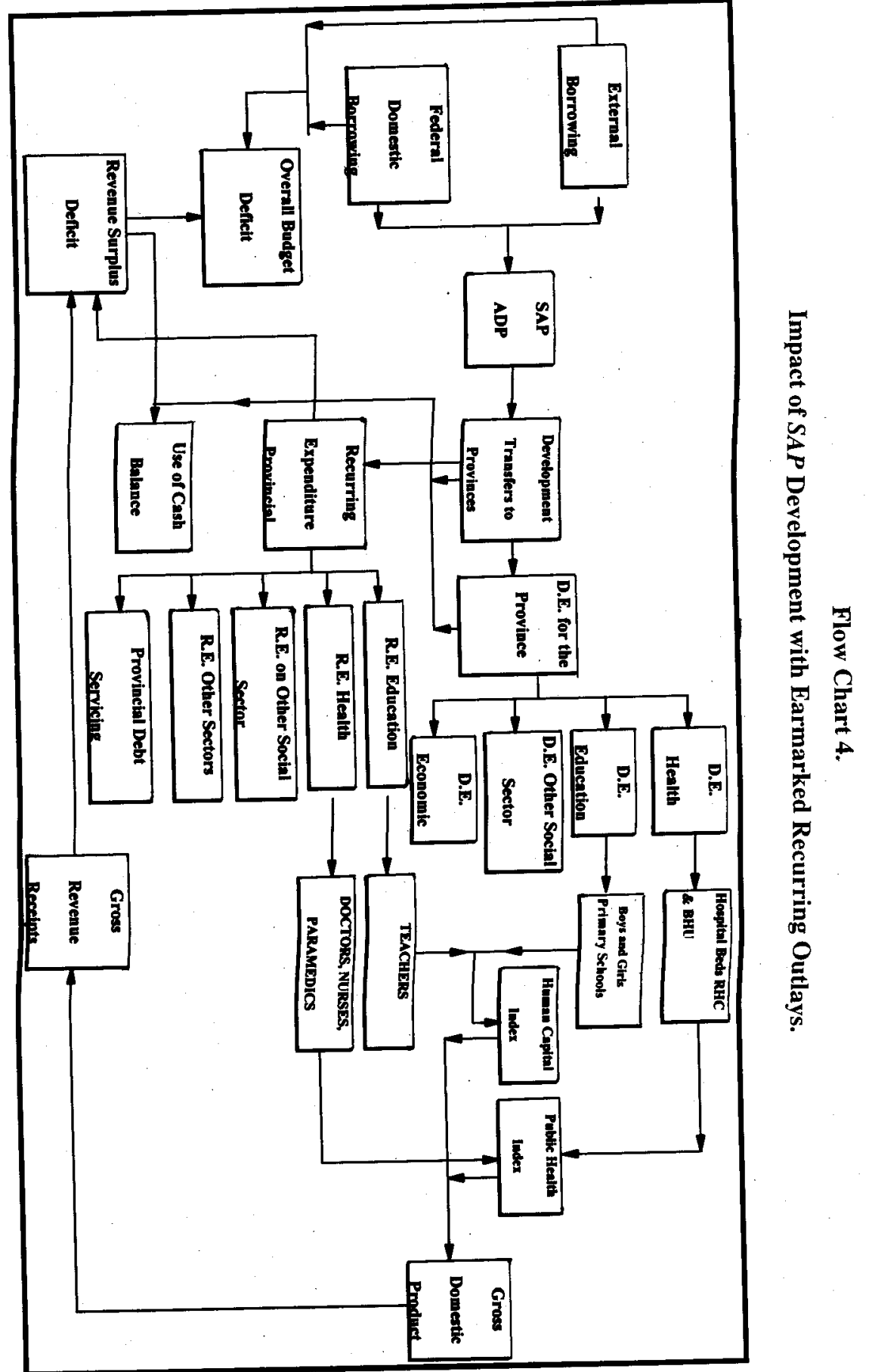

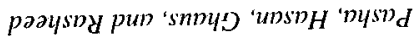


Table 3

Impact of SAP Development with Recurring Expenditure on Macro-economy

A. Social Sector Variable

Primary Participation Rate 1992-93 1994-95

2002-03

Teacher to School Ratio

99.42

0.45

1.20 $104.13 \quad 134.47$

45.21

1.27

6.02

$49.58 \quad 67.70$

2.29

0.059

0.021

2.376

3.085

3.68

$-0.031$

$-0.189$

Hospital Beds

52228

3.542

3.258

Rural Health Centre (RHC)

1375

0

142

$55486 \quad 68424$

Doctor to Bed Ratio

0.438

1739

69

3534

Doctor to RHCs Ratio

8.38

0.013

0.001

0.472

0.621

0.858

$-0.085$

Human Capital Index

136.22

7.974

6.704

0.04

0.86

Public Health Index

241.38

139.45

189.88

4.98

3.57

272.83

410.64

\section{B. Fiscal Variables}

Provincial Dev. Expenditure (Social)

Provincial Rec. Expenditure (Social)

Debt Servicing

Gross Revenue Receipt

Use of Cash Balances

C. Macro Variables

Overall Budget Deficit

Value-added in Agriculture

Value-added in Manufacturing

18,122

590

256

52,442

$916 \quad 1,050$

20,548

203

775

91,223

30

673

4,239

444

499

Value-added in Other Sectors

Gross Domestic Product

$\begin{array}{rrr}\mathbf{9 3 , 5 2 0} & 1,577 & 5,896 \\ \mathbf{1 2 2 , 8 9 4} & 27 & 645 \\ \mathbf{8 5 , 5 3 4} & 4 & 297 \\ \mathbf{2 7 7 , 3 3 7} & 23 & 709 \\ \mathbf{5 4 2 , 2 9 1} & 55 & 1,792\end{array}$

Note: Numbers in Italics indicate Baseline Simulation Results.

Numbers in sections B \& C represent change from the baseline simulation due to the Rs 1 Billion increase for three consecutive years. 
earlier programme as shown in Table 2. The overall deficit figures have also gone up by over 100 percent. These rising budgetary deficits of the provincial and federal governments due to recurring liabilities are alarming and this will be one of the key factors in making the SAP-type financing unsustainable in the long run.

The key public policy issue that needs to be addressed in this context is the alternative available to the governments to make the $S A P$ sustainable in the long run. One of the important policies that the government may undertake in this context is to improve the revenue position of the governments through higher fiscal efforts.

\section{3. $S A P$ with Resource Mobilisation}

It is clear that a $S A P$-type programme, financed largely through transfer of funds to the sub-national government, is not financially sustainable in the long run. The high and rising debt servicing liabilities alongwith other operational requirements increase the fiscal gap not only at the provincial but also at the overall national level. However, if $S A P$ is launched simultaneously with a strategy of higher resource mobilisation by the provincial governments, the scenario can change dramatically. Higher fiscal effort results in not only a higher provincial expenditure but also prevents a deterioration in the provincial and national budgetary position. Increased provincial expenditure implies higher expenditure and higher inputs in social sectors, and therefore higher social sector outputs, which exacerbates the stimulatory impact on the GDP and, in turn, gross provincial receipts (see Flow Chart 5).

In terms of magnitudes, Table 4 shows the key impacts of $S A P$ alongwith higher provincial resource mobilisation. There are gains not only in the social sector provisions, reflected in the improvement in the social sector indices, but also in the fiscal status of the provincial governments. There is an immediate draw down in the use of cash balances (of over Rs 300 million) and also a substantial reduction in the overall budget deficit of about Rs 3 billion in the long run. Also, there is a significant increase in the growth in all the major sectors of the economy.

On the whole, it appears that social sector development programmes like the $S A P$ not only have social benefits and improve the quality of life of the masses, but that they also generate long-run economic benefits in terms of higher GDP growth. $S A P$-type of initiative will be successful if an effort is made by the provincial governments to enhance their own revenues; otherwise such programmes may affect the public finances of the country adversely.

\section{CONCLUDING REMARKS}

This paper demonstrates that Pakistan does poorly in the social indicators partly because of lower public outlays on the social sectors. It examines the financial sustainability of a higher level of investment in these sectors through the Social Action Programme in view of the absence of any obvious source of revenue for 
Table 4

Impact of SAP. Development with Resource Mobilisation on Macro-economy

\begin{tabular}{|c|c|c|c|}
\hline & $1992-93$ & $1994-95$ & $2002-03$ \\
\hline \multicolumn{4}{|l|}{ A. Social Sector Variable } \\
\hline \multirow[t]{4}{*}{ Primary Participation Rate } & 99.42 & 0.04 & 0.75 \\
\hline & & 104.13 & 134.47 \\
\hline & 45.21 & 1.41 & 9.50 \\
\hline & & 49.58 & 67.70 \\
\hline \multirow{4}{*}{ Teacher to School Ratio } & 2.29 & 0.005 & 0.039 \\
\hline & & 2.376 & 3.085 \\
\hline & 3.68 & -0.305 & -0.266 \\
\hline & & 3.542 & 3.258 \\
\hline \multirow[t]{2}{*}{ Hospital Beds } & 52228 & 0 & 217 \\
\hline & & 55486 & 68424 \\
\hline \multirow[t]{2}{*}{ Rural Health Centre (RHC) } & 1375 & 0 & 151 \\
\hline & & 1739 & 3534 \\
\hline \multirow{2}{*}{ Doctor to Bed Ratio } & 0.438 & 0.001 & 0.006 \\
\hline & & 0.472 & 0.621 \\
\hline \multirow[t]{2}{*}{ Doctor to RHCs Ratio } & 8.38 & 0.023 & -0.190 \\
\hline & & 7.974 & 6.704 \\
\hline \multirow[t]{2}{*}{ Human Capital Index } & 136.22 & 0.02 & 0.89 \\
\hline & & 139.45 & 189.88 \\
\hline \multirow[t]{2}{*}{ Public Health Index } & 241.38 & 0.59 & 7.93 \\
\hline & & 272.83 & 410.64 \\
\hline \multicolumn{4}{|l|}{ B. Fiscal Variables } \\
\hline Provincial Dev: Expenditure (Social) & 18,122 & 1,060 & 587 \\
\hline Provincial Rec. Expenditure (Social) & 52,442 & 429 & 2,304 \\
\hline Debt Servicing & 20,548 & 183 & 145 \\
\hline Gross Revenue Receipt & 91,223 & 1,161 & 6,817 \\
\hline Use of Cash Balances & 4,239 & $(303)$ & $(1,634)$ \\
\hline \multicolumn{4}{|l|}{ C. Macro Variables } \\
\hline Overall Budget Deficit & $\mathbf{9 3 , 5 2 0}$ & 565 & $(2,750)$ \\
\hline Value-added in Agriculture & 122,894 & 18 & 688 \\
\hline Value-added in Manufacturing & 85,534 & 9 & 542 \\
\hline Value-added in Other Sectors & 277,337 & 27 & 970 \\
\hline Gross Domestic Product & 542,291 & 333 & 2,822 \\
\hline
\end{tabular}

Note: Numbers in Italics indicate Baseline Simulation Results.

Numbers in sections B \& C represent change from the baseline simulation due to the Rs 1 Billion increase for three consecutive years. 
financing the downstream operation and the maintenance expenditures of the facilities created. The basic conclusion is that since education and health are recurring expenditure-intensive, the sustainability of the programme is in doubt. The issue is quantitatively examined in the context of a large macro-econometric model, with detailed modules for public finances and the social sectors.

Policy simulations of the model in a medium- to long-run setting lead to some striking conclusions. An allocation of funds through the Social Action Programme can lead to gains in the GDP and improvements in the social indicators. But this programme can exacerbate the problem of the budget deficit. Even if some provisions are made for financing the recurring expenditure within this programme, financial sustainability will remain a problem after the end of the programme. Consequently, the study makes a strong case for combining more intensive efforts at provincial resource mobilisation alongwith the launching of the SAP.

\section{REFERENCES}

Lloyd-Ellis, H. (1993) Enterprise, Education, and the Distribution of Gains from Growth. Paper presented at the "Macro-economic Theory" conference. University of Victoria, Canada.

Pasha, H., M. A. Hasan, A. Ghaus, and A. Rasheed (1995) Integrated Social Policy Macro-economic Planning Model for Pakistan. Karachi: SPDC publication. Rostow, W. W. (1960) The States of Economic Growth: A Non-Communist Manifesto. Cambridge: Cambridge University Press.

Tan, J., and A. Mingat (1992) Education in Asia: A Comparative Study of Cost and Financing. The World Bank.

Urquidi, V. L. (1971) The So-called Social Aspects of Economic Development. In A. B. Mountjoy (ed) Developing the Underdeveloped Countries. Macmillan Press. 76-86. 